\title{
Suppression of Powdery Mildews by UV-B: Application Frequency and Timing, Dose, Reflectance, and Automation
}

\author{
A. Suthaparan, Department of Plant Sciences, K. A. Solhaug, Department of Ecology and Natural Resource Management, N. Bjugstad, \\ Department of Mathematics and Technology, and H. R. Gislerød, Department of Plant Sciences, Norwegian University of Life Sciences, 1432 As, \\ Norway; D. M. Gadoury, Department of Plant Pathology and Plant-Microbe Biology, Cornell University, New York State Agricultural \\ Experiment Station, Geneva, NY 14456; and A. Stensvand, Norwegian Institute of Bioeconomy Research, P.O. Box 115, 1431 Å, Norway
}

\begin{abstract}
Suthaparan, A., Solhaug, K. A., Bjugstad, N., Gislerød, H. R., Gadoury, D. M., Stensvand, A. 2016. Suppression of powdery mildews by UV-B: application frequency and timing, dose, reflectance, and automation. Plant Dis. 100:1643-1650.

Disease-suppressive effects of nighttime applications of ultraviolet-B (UV-B) were investigated at two irradiance levels $\left(1.6\right.$ or $\left.0.8 \mathrm{~W} / \mathrm{m}^{2}\right)$ in strawberry and rosemary plants inoculated with Podosphaera aphanis or Golovinomyces biocellatus, respectively. Plants were exposed to each irradiance level every third night for either 9 or 18 min, every night for either 3 or $6 \mathrm{~min}$, or three times every night for either 1 or $2 \mathrm{~min}$. Thus, over time, all plants received the same cumulative dose of UV-B, and severity of powdery mildew was reduced by 90 to $99 \%$ compared with untreated controls in both crops. Use of polished aluminum lamp reflectors and UV-B reflective surfaces on greenhouse benches significantly increased treatment efficacy. An automated apparatus consisting of an

adjustable boom with directed airflow was used to move UV-B lamps over greenhouse benches at 25 or $50 \mathrm{~cm} / \mathrm{min}$. Directed airflow moved leaves on the subtending plants to better expose upper and lower surfaces to UV-B but directed airflow actually decreased the efficacy of UV-B treatments, possibly by dispersing conidia from lesions before they were exposed to a lethal dose of UV-B. Results indicate broad applicability of nighttime applications of UV-B to suppress powdery mildews, and that cumulative UV-B dose is an overriding factor determining efficacy. Finally, enhanced suppression on shaded or obscured tissues is more likely to be affected by reflective bench surfaces than through attempts to physically manipulate the foliage.
\end{abstract}

Powdery mildews are among the most economically important plant diseases, and they are a significant threat to numerous crop plants worldwide. The intensive use of fungicides against powdery mildews, coupled with their propensity to develop resistance to broad classes of fungicides, makes them especially problematic to control in the absence of mildew-resistant varieties (Hollomon and Wheeler 2002; McGrath 2001; McGrath et al. 1996). Biological control of powdery mildews has been attempted in several pathosystems (Kiss 2003; Romero et al. 2007), and there are some reports of success under practical conditions (Paulitz and Belanger 2001; Romero et al. 2007). However, powdery mildews remain a destructive group of fungal pathogens. The damage caused by powdery mildews can be especially severe when crops are grown in greenhouse and high-tunnel production systems (Jones et al. 2001; Willocquet et al. 2008).

Manipulation of specific light qualities and ultraviolet (UV) radiation has shown great potential in management of powdery mildews in several crop plants. In early work, suppression of grape powdery mildew (Erysiphe necator) has been reported using a mobile device (Michaloski 1991) to apply germicidal UV (peak $254 \mathrm{~nm}$ ) under field conditions (Gadoury et al. 1992). Exposure of rose plants to continuous lighting significantly reduced sporulation of Podosphaera pannosa and reduced the subsequent severity of powdery mildew (Mortensen et al. 2007; Suthaparan et al. 2010a). Red light was shown to significantly suppress sporulation in $P$. pannosa on rose (Suthaparan et al. 2010b) and severity of $P$. xanthii on cucumber (Wang et al. 2010). Supplementing UV-B radiation to duplicate the UV-B spectrum of solar radiation has been reported to decrease the germination and mycelial growth of E. necator on leaf disks of grape (Willocquet et al. 1996) but increased severity of Microsphaera

Corresponding author: A. Suthaparan; E-mail: aruppillai.suthaparan@nmbu.no Accepted for publication 2 March 2016.

http://dx.doi.org/10.1094/PDIS-12-15-1440-RE

(C) 2016 The American Phytopathological Society alphitoides on oak (Newsham et al. 2000). Suppression of rose and cucumber powdery mildews by brief exposure to UV-B during night has been reported previously (Suthaparan et al. 2012a,b), and nighttime applications of UV-B were even more effective in suppressing powdery mildews (Suthaparan et al. 2012c, 2014). Commercial units to apply UV-C to plants are now available (Cleanlight BV), although the units have not yet been evaluated in peer-reviewed journals. Most recently, Janisiewicz et al. (2015) reported that imposition of a dark period following exposure of strawberry plants to shortwave UV radiation (peak $254 \mathrm{~nm}$ ) also increased the degree to which $P$. aphanis was suppressed.

In the present study, we sought to refine the application of the UV-B technology to enhance adoption in greenhouse and high-tunnel production systems and demonstrate efficacy of the technology against two diverse powdery mildews. P. aphanis (syn. Sphaerotheca macularis) and Golovinomyces biocellatus cause powdery mildew on strawberry (Fragaria $\times$ ananassa) and rosemary (Rosmarinus officinalis L.), respectively. Both pathogens cause severe losses in their respective host plants, and both hosts are commonly produced in high-tunnel and greenhouse systems. Our present objectives were to elucidate how variations in irradiance (watts per square meter), as well as frequency and duration of exposure events, might interact to affect levels of suppression achieved by UV-B treatments. Furthermore, we employed polished aluminum reflectors for UV-B lamps and for bench surfaces to enhance the efficacy of UV-B treatments, and investigated the use of directed airflow to increase exposure on obscured or shaded plant parts. Finally, we developed and evaluated a robotic boom to suspend and move UV-B lamps over greenhouse benches during automated nighttime UV-B treatments.

\section{Materials and Methods}

Plant propagation. The nodal region of uniform runner tips of June-bearing 'Korona' strawberry were planted in plastic pots $(12 \mathrm{~cm}$ in diameter) filled with standard growth medium (VEKSTTORV; Ullensaker Almenning). Both the runner and mother plants were maintained at $18.6 \pm 5.4^{\circ} \mathrm{C}$ and relative humidity (RH) of $75 \pm 20 \%$. 
Plants were watered when needed with a complete nutrient solution prepared by mixing Kristalon Indigo and YaraLiva Calcinite (1:1 [vol/vol]; Yara International ASA), with an electrical conductivity of $1.5 \mathrm{mS} / \mathrm{cm}$. Sixteen hours of daily growth light (GL) was provided by solar irradiance supplemented with highpressure sodium (HPS) lamps (Lucalox LU400/XO/T/40; GE Lighting), with minimum photosynthetic photon flux (PPF; 400 to $700 \mathrm{~nm}$ ) of $100 \pm 10 \mu \mathrm{mol} / \mathrm{m}^{2} / \mathrm{s}$ at plant height, as described previously (Suthaparan et al. 2012b). Lamps were turned on whenever solar irradiance was $<200 \mathrm{~W} / \mathrm{m}^{2}$. Once the adventitious roots were established (10 to 14 days), runner plants (new clone plants) were separated from the strawberry mother plant by snipping off the runners. New clone plants were used for experiments once they developed two leaves.

Seed of 'Rosy' rosemary were sown in plastic pots and maintained as explained above for strawberry. Immediately prior to the start of the experiments, plants were thinned to five plants per pot, and each plant had four to seven leaves.

Inoculum preparation and maintenance. $P$. aphanis was isolated from a diseased leaf of a strawberry plant grown in an experimental field. Similarly, isolates of $G$. biocellatus were isolated from greenhouse-grown rosemary. Aseptic cultures of clonal isolates were achieved through sequential transfer of the respective pathogens to petri dishes containing surface-sterilized strawberry or rosemary leaves on water agar, as described previously (Suthaparan et al. 2012 b). Inoculum was transferred to healthy strawberry or rosemary plants with young emerging leaves by touching diseased leaves from the petri plate cultures onto healthy leaves. Inoculated plants were maintained in an isolated growth chamber with $14 \mathrm{~h}$ of daily lighting provided by high-pressure mercury lamps (Powerstar HQI-BT 400 W/D day light; Osram $\mathrm{GmbH}$ ), with PPF of $100 \pm 10 \mu \mathrm{mol} / \mathrm{m}^{2} / \mathrm{s}$, temperature of $25 \pm 1{ }^{\circ} \mathrm{C}$, and $\mathrm{RH}$ of $75 \pm 3 \%$. A supply of inoculum was ensured by regular placement of young, healthy plants together with plants bearing powdery mildew colonies in a growth chamber 10 days before the start of each experiment. After exposure to
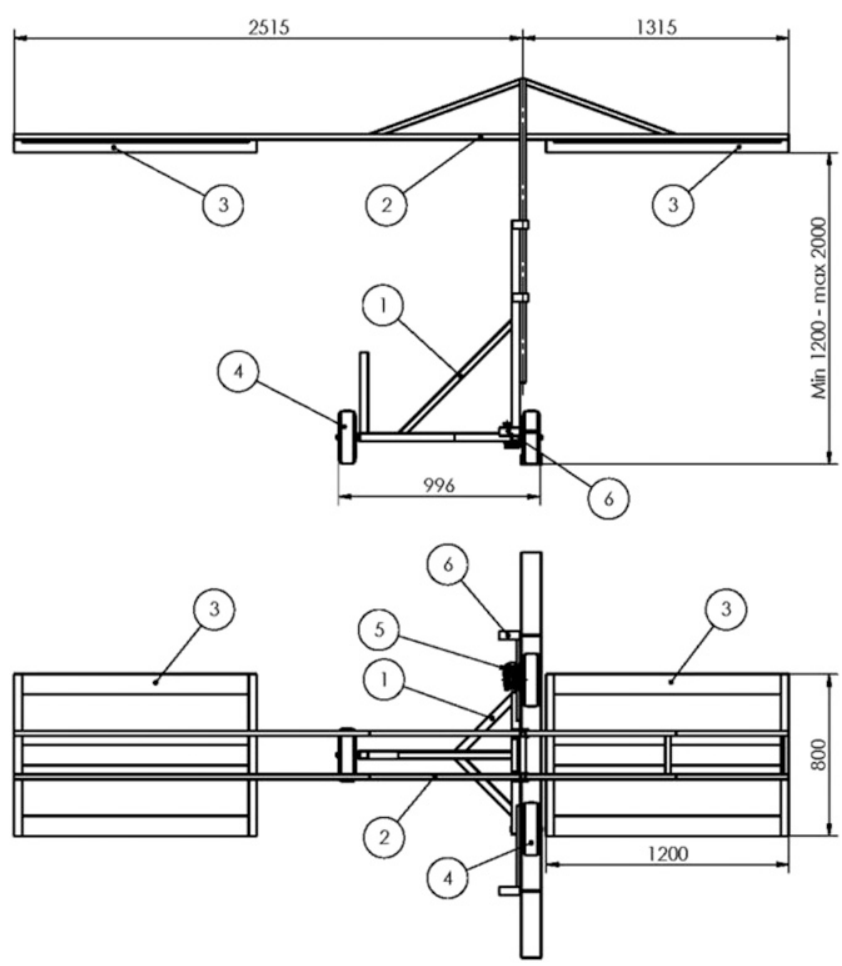

Fig. 1. Schematic drawings of automated ultraviolet-B (UV-B) boom in millimeter scale made by 40 -by-40-mm steel profiles 1, Supporting steel profile; 2 , horizontal steel profile; 3, 120-cm UV-B fluorescence tube; 4 , wheel with dimension of 260 by $85 \mathrm{~mm}$; 5 , electric motor with power transmission gears which reduce the motor's rpm by 2,400:1; and 6 , circuit breaker on-off switch which controls directionality of the boom once hitting the L-shaped metal plate placed at each end of the track. infection and incubation, plants with three well-developed leaves with powdery mildew were selected and used as inoculum plants for the strawberry experiments. A supply of inoculum for experiments with rosemary plants was produced in the same manner.

Experimental conditions. Greenhouse experiments were conducted with air temperature, RH, GL, and watering conditions as described above. For UV-B treatments, UV-B irradiance was supplied by $120-\mathrm{cm}$ UV-B fluorescent tubes (model UVB-313EL; Q-PANEL Lab Products). Two independent experiments were conducted in all cases, unless otherwise mentioned.

UV-B irradiance level, duration, and application frequency. Each treatment consisted of six pots, each containing a single healthy strawberry plant, placed in two rows of three pots. Each plant had developed two true leaves at the start of the experiments. Two pots containing strawberry plants heavily infected with powdery mildew (inoculum plants) were placed between the rows to allow natural spread of the inoculum. All treatments were exposed to a minimum of $230 \pm 20 \mu \mathrm{mol} / \mathrm{m}^{2} / \mathrm{s}$ GL during $16 \mathrm{~h}$ of daily lighting. UV-B treatments took place immediately after dark (approximately $1 \mathrm{~h}$ after sunset) and were followed by darkness. The treatments were as follow: (i) GL only, (ii) UV-B at $0.8 \mathrm{~W} / \mathrm{m}^{2}$ for 18 min once in 3 days, (iii) UV-B at $0.8 \mathrm{~W} / \mathrm{m}^{2}$ for $6 \mathrm{~min}$ daily, (iv) UV-B at $0.8 \mathrm{~W} / \mathrm{m}^{2}$ for $2 \mathrm{~min}$ three times daily (approximately $4 \mathrm{~h}$ of darkness between each UV-B exposure), (v) UV-B at $1.6 \mathrm{~W} / \mathrm{m}^{2}$ for $9 \mathrm{~min}$ once in 3 days, (vi) UV-B at $1.6 \mathrm{~W} / \mathrm{m}^{2}$ for $3 \mathrm{~min}$ daily, and (vii) UV-B at $1.6 \mathrm{~W} / \mathrm{m}^{2}$ for $1 \mathrm{~min}$ three times daily (approximately $4 \mathrm{~h}$ of darkness between each UV-B exposure). Number of leaves and percentage of diseased area for each leaf was assessed 18 days after the UV-B exposure started. Mean percentage of diseased leaf area per plant was calculated.

A similar experiment was conducted with rosemary. Assessments were done 18 days after UV-B exposure started. Percent diseased leaf area was recorded for the five leaves ( $>2 \mathrm{~cm}$ in length) with the highest severity on each plant. Five plants per pot were assessed and mean values per pot were used as replicates.

Use of reflective surfaces on greenhouse benches and efficacy of UV-B treatments. An experiment was conducted with strawberry plants wherein the greenhouse benches were either covered with perforated white plastic (Vattex; Norgro AS) that was minimally reflective with respect to UV-B or covered with polished aluminum foil to reflect a high percentage of UV-B reaching the bench from the overhead lamps. Light treatments were as described above, with the following modifications: (i) GL with white perforated plastic bench cover only, (ii) GL with aluminum foil as a reflective bench cover, (iii) UV-B at $1.6 \mathrm{~W} / \mathrm{m}^{2}$ for 3 min daily with white plastic bench cover, or (iv) UV-B at $1.6 \mathrm{~W} / \mathrm{m}^{2}$ for 3 min daily with aluminum foil as a reflective bench cover. Disease assessments were as described above and the experiment was repeated three times.

An automated boom for UV-B treatments. The framework of an automated boom was constructed from 40-by-40-mm square steel tubing. The frame of the boom rode upon 260-by-85-mm wheels (Fig. 1) within a metal channel on the greenhouse floor. The wheels were driven by an electric motor of $0.18 \mathrm{~kW}$ (model MS63A-4; Busck \& $\mathrm{Co} \mathrm{AB}$ ) with power transmission gears (models SB040 and SB030; Busck \& $\mathrm{Co} A B$ ) that reduced the motor's rpm by 2,400:1. A frequency converter (VLT Micro Drive FC 51; Danfoss Drives) connected to the electric motor was used to adjust the speed at which the boom moved over the subtending greenhouse bench (Fig. 2). A programmable digital time switch (model MM7596 230 V; Micro Matic Hugo Müller $\mathrm{GmbH}$ ) controlled timing of the power supplied to the drive motor and UV-B lamps, and prewired limit switches (model CE 70.0 EM/2; Camden Electronics Ltd.) were used to control the direction of the boom or to turn the unit off once it hit an L-shaped metal plate placed within the metal channel at each end.

Three UV-B fluorescence tubes of the type mentioned above were mounted on each of two horizontal arms, one arm with and one without an air blower (model QK10A-4EM.78.CF; Ziehl-Abegg AG). The blower provided a directed air stream that moved leaves on the subtending plants with the intent of improving exposure of shaded or obscured tissues to UV-B. Air was directed at the plant 
canopy at an angle of approximately $45^{\circ}$ from the bench surface at a wind speed of approximately $2.5 \pm 0.3 \mathrm{~m} / \mathrm{s}$. The energy supplied to each plant by the UV-B lamps was $502.4 \mathrm{~J} / \mathrm{m}^{2} /$ day (at the speed of $25 \mathrm{~cm} / \mathrm{min}$ ) (Fig. 3).

Each treatment included two rows with six mildew-free strawberry plants in each, and four inoculum plants (as described above) placed between the rows (pots were placed at a $30-\mathrm{cm}$ distance within and between rows). All treatments received $16 \mathrm{~h}$ of GL delivering a minimum of $110 \pm 10 \mu \mathrm{mol} / \mathrm{m}^{2} / \mathrm{s}$, and UV-B treatments took place immediately after the start of the dark period. Treatments were (i) $16 \mathrm{~h}$ of GL only, (ii) UV-B radiation followed by darkness, and (iii) UV-B radiation + air movement followed by darkness. A similar experiment was conducted using three plants in each of two rows, with two inoculum plants placed between the rows, wherein the speed of the automated boom movement was $50 \mathrm{~cm} / \mathrm{min}$, resulting in a UV-B dose of $228.3 \mathrm{~J} / \mathrm{m}^{2} /$ day delivered to each plant (Fig. 3).

The number of unfolded leaves, the percentage of the adaxial and abaxial leaf area colonized, the number of colonized and uncolonized runner plants, total leaf area per plant, and dry weight of aboveground plant parts were assessed 24 days after the start of the experiment. For dry weight assessments, harvested plants were kept at $70^{\circ} \mathrm{C}$ for 10 days. All experiments were repeated twice.

Addition of polished reflectors to lamps on the automated boom. Polished aluminum reflectors (Glamox REFL SYM SKA 136, part number C27136300; BU Glamox Luxo Lighting) were installed behind each UV-B lamp to increase the amount of UV-B reaching the plants beneath the automated boom. Experiments were then conducted with rosemary plants using the automated boom at a speed of $50 \mathrm{~cm} / \mathrm{min}$ with the air blower turned off. Three pots of diseasefree rosemary plants with four to seven unfolded leaves on each plant were placed in each of two rows per treatment, with two inoculum plants placed between the rows. Spacing was $15 \mathrm{~cm}$ between pots within and between rows. All treatments received $16 \mathrm{~h}$ of GL delivering a minimum of $110 \pm 10 \mu \mathrm{mol} / \mathrm{m}^{2} / \mathrm{s}$, and UV-B treatments took place immediately after start of the dark period. Treatments were as follows: (i) $16 \mathrm{~h}$ of GL only, (ii) nightly UV-B irradiance of 228.3 $\mathrm{J} / \mathrm{m}^{2} /$ day using lamps without reflectors, and (iii) alternate-night UV-B irradiance of $395.8 \mathrm{~J} / \mathrm{m}^{2} /$ day using lamps with polished aluminum reflectors (Fig. 3).

Disease severity and plant growth were assessed as described previously. In addition, dry weight of the aboveground plant parts for all five plants per pot were measured together (dry weight per replicate) at the conclusion of the experiment.

Recording of environmental conditions. Irradiance received from high-pressure mercury and HPS lamps at plant height was recorded with a digital Lambda LI-185B photometer (LI-COR Inc.) containing a quantum sensor LI-190. Spectral qualities of all lamps used in the present study were measured using an Optronic spectroradiometer (model 756; Optronic Laboratories). UV-B irradiance was measured using a SKYE SKU430 sensor (Skye instruments Ltd.) calibrated for the UV-B sources by an Optronic spectroradiometer (model 756; Optronic Laboratories). Spectral reflectance of the bench covers within a range of 250 to $450 \mathrm{~nm}$ was measured using

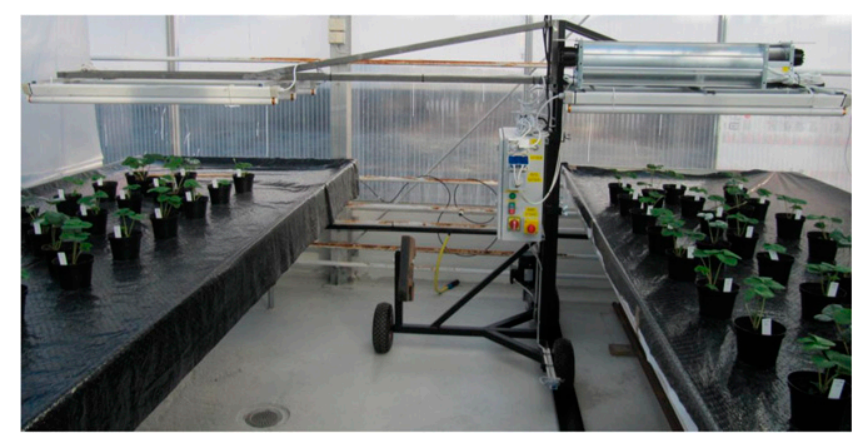

Fig. 2. Picture of the boom operating in an experimental greenhouse with strawberry plants. Left arm with UV lamps only and right arm with UV lamps and an air blower meant to increase the exposure of UV-B on the abaxial leaf sides. a spectroradiometer (model SD2000; OceanOptics) connected to an integrating sphere (ISP-50-REFL; OceanOptics). To obtain measurements of spectral reflectance, bench covers were placed on the port of the sphere and illuminated with a deuterium lamp (DH2000; OceanOptics) via 600- $\mu \mathrm{m}$ optical fiber within the sphere in conjunction with a collimating lens within the sphere compared with a white reference tile (WS-2; Top Sensor Systems). The percent reflectance was calculated on the basis of a dark spectrum and a reference spectrum from a white reference tile. Air temperature and $\mathrm{RH}$ was recorded at 5-min intervals with a Priva greenhouse computer (Priva) with dry- and wet-bulb thermosensors deployed at plant canopy level. Air velocity was measured by a compact vane anemometer (model Testo 416; Testo Inc.).

Data analysis. Completely randomized designs with the general linear model procedure (Minitab, version 16.0; Minitab Corp.) were used for data analysis. Although treatments were handled as a fixed factor, experimental repeat, replicates within the experiments, and experimental repeat-treatment interactions were all treated as random factors. Normality and homogeneity of variance of the data were checked to determine whether appropriate transformation was necessary and, if so, data were transformed before analysis and back-transformed data are presented in the results. Mean comparisons were performed with Tukey's pairwise comparisons at $P=0.05$. Data analysis and mean comparisons were performed separately whenever experimental repeat or experimental repeattreatment interactions were significant.

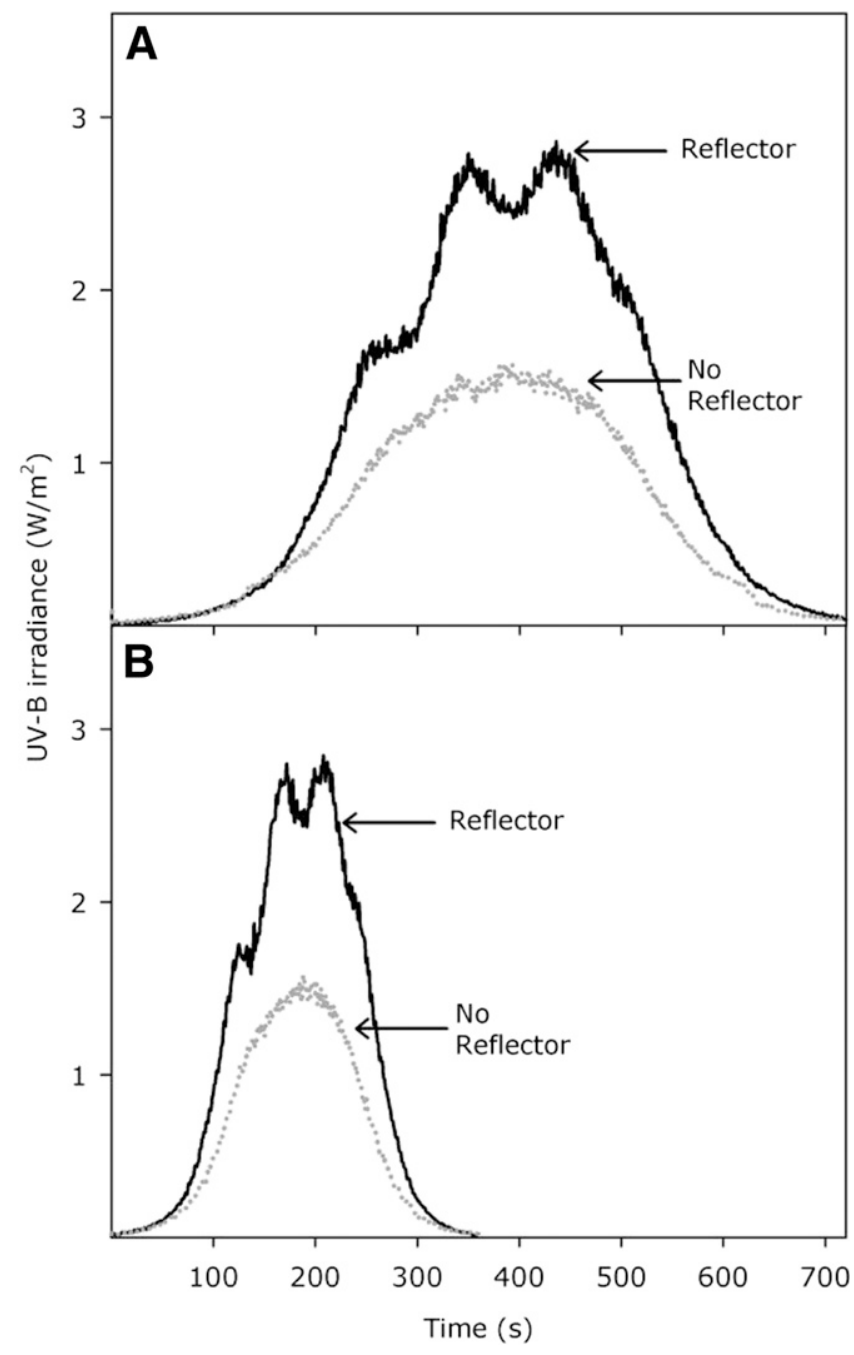

Fig. 3. Distribution of ultraviolet-B (UV-B) irradiance received by individual plants (adaxial leaf surfaces) measured at canopy level during exposure to the UV-B fluorescence lamps of the automated boom; boom speeds of $A, 25$ to $B, 50 \mathrm{~cm} / \mathrm{min}$ and with or without reflectors. Data were logged every second. 
In the experiment with different doses and exposure times of UV-B, data were handled in a single factor design. In the reflective bench cover experiments, data were handled as two factors (UV-B treatment and reflective bench cover). Data were handled in a single-factor design, with three levels in all experiments equipped with the automated boom.

\section{Results}

Effects of UV-B irradiance level, duration, and application frequency on powdery mildew severity. UV-B treatments $(P<$ $0.0001)$ and experimental repeat $(P=0.038)$ both had a significant effect on powdery mildew severity in strawberry, whereas the interaction between experiment repeat and UV-B treatment did not

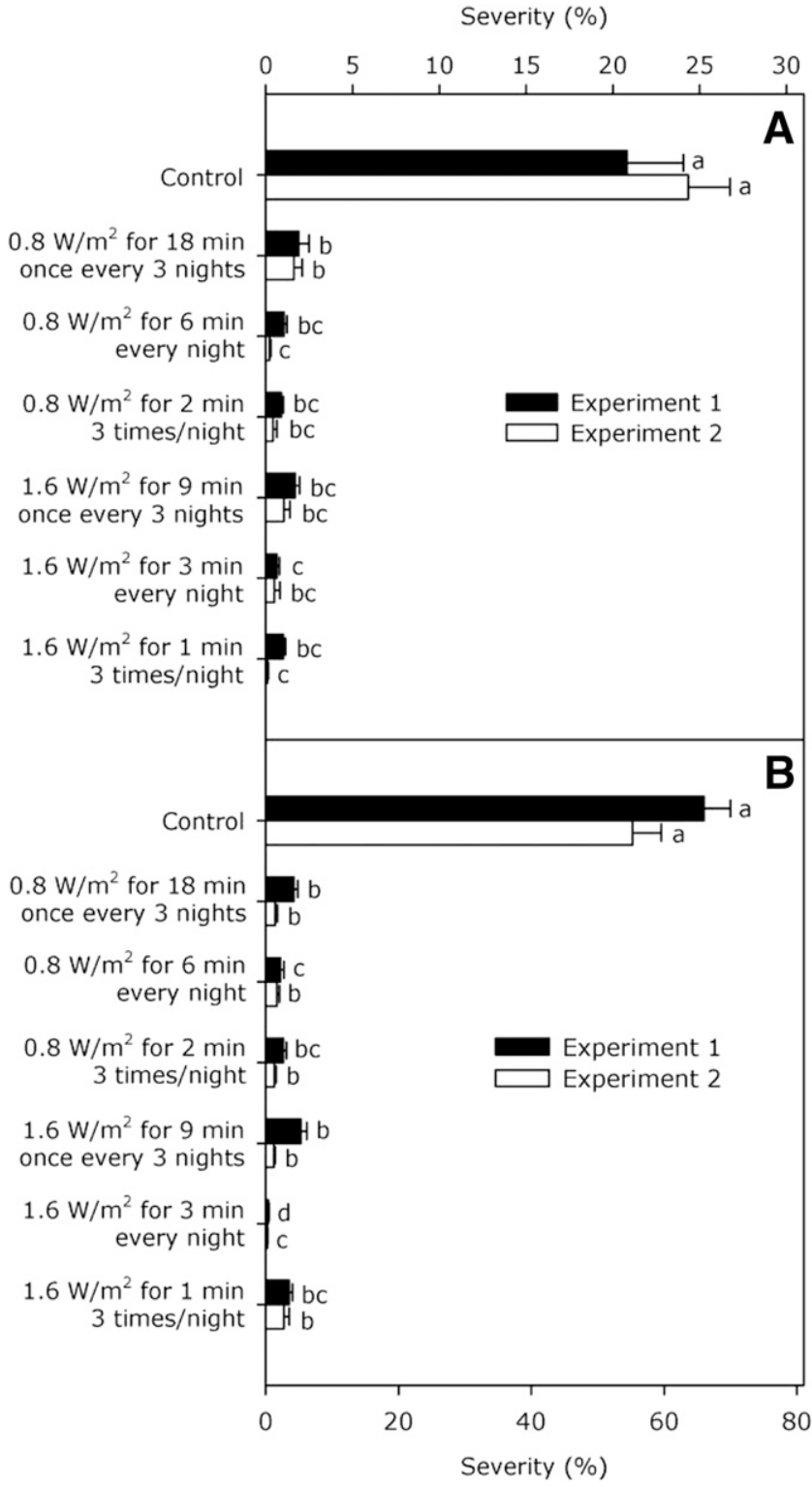

Fig. 4. Effect of ultraviolet-B (UV-B) applications of different irradiance levels, duration, and frequency on severity of powdery mildew on $\mathbf{A}$, Korona strawberry and $\mathbf{B}$, Rosy rosemary. All plants were exposed to $16 \mathrm{~h}$ of growth light, including the nontreated control, and UV-B treatments took place during the dark period following growth light illumination. Disease severity was assessed as percentage of the leaf surfaces colonized 18 days after treatments were initiated. Assessed severity was adjusted to the quantity $(1+$ severity), log-transformed prior to analysis to induce homogeneity of variance, and then back-transformed to percentages for presentation. Bars represent the mean and standard error within each of two independent experiments, each with 6 replicate plants for strawberry ( $n=12$ plants) and six replicate pots with 5 plants per pot ( $n=60$ plants) for rosemary. Within experiments, different letters indicate significant differences in mean values at $P=0.05$. significantly affect severity. Therefore, the results are presented separately for each of the experimental repeats (Fig. 4). All UV-B treatments significantly reduced severity of powdery mildew compared with untreated controls. Severity of infection in strawberry was reduced to a level of less than $10 \%$ of the level observed in untreated strawberry plants in experiments 1 and 2 (Fig. 4A). The mean severity of strawberry powdery mildew under GL was $20.8 \%$ in experiment 1 and $24.4 \%$ in experiment 2 (Fig. 4A).

There were relatively small and often statistically insignificant differences in disease severity among equivalent UV-B doses that were applied to strawberry plants as single exposures once per night, every 3 nights, or as multiple events in a single night. When strawberry plants were exposed to UV-B at $0.8 \mathrm{~W} / \mathrm{m}^{2}$ for 18 min once every three nights, foliar mildew severity was 1.9 and $1.6 \%$ in experiments 1 and 2, respectively. Exposure of strawberry plants to UV-B at 0.8 $\mathrm{W} / \mathrm{m}^{2}$ for 6 min once per night reduced severity to 1 and $0.2 \%$ in experiments 1 and 2, respectively. When exposed to UV-B at $0.8 \mathrm{~W} / \mathrm{m}^{2}$ for $2 \mathrm{~min}$ three times per night, severity was reduced to 0.9 and $0.4 \%$ in experiments 1 and 2, respectively (Fig. 4A). Exposure of strawberry plants to UV-B at $1.6 \mathrm{~W} / \mathrm{m}^{2}$ for 9 min once every three nights reduced severity to 1.7 and $1.0 \%$ in experiments 1 and 2, respectively (Fig. 4A). Exposure of strawberry plants to UV-B at $1.6 \mathrm{~W} / \mathrm{m}^{2}$ for 3 min once per night reduced powdery mildew severity to 0.6 and $0.5 \%$ in experiments 1 and 2, respectively (Fig. 4A). Exposure of strawberry plants to UV-B at $1.6 \mathrm{~W} / \mathrm{m}^{2}$ for $1 \mathrm{~min}$ three times per night reduced powdery mildew severity to 1 and $0.1 \%$ in experiments 1 and 2, respectively (Fig. 4A). No symptoms of phytotoxicity from UV-B treatments were observed on strawberry plants.

There was a significant effect upon severity of powdery mildew on rosemary for experimental repeat $(P=0.011$ and 0.002 , respectively), UV-B treatment $(P<0.0001$ for both), and interaction between experimental repeat and UV-B treatment $(P=0.001$ and 0.004 , respectively). All UV-B treatments were significantly different from the untreated control. Similar to results obtained for strawberry, there were relatively small and often statistically insignificant differences in disease severity among equivalent UV-B doses that were applied to rosemary plants as multiple events or one time in a single night or every third night. However, application of UV-B at $1.6 \mathrm{~W} / \mathrm{m}^{2}$ for 3 min every night showed the significantly lowest severity compared with all other treatments. The mean severity of the untreated control under GL was $66 \%$ in experiment 1 and $55.2 \%$ in experiment 2 (Fig. 4B). Severity of powdery mildew was 4.2 and $1.4 \%$ in experiments 1 and 2, respectively, when rosemary plants were exposed to UV-B at $0.8 \mathrm{~W} / \mathrm{m}^{2}$ for 18 min once in 3 days. Severity of powdery mildew on rosemary plants exposed to UV-B at $0.8 \mathrm{~W} / \mathrm{m}^{2}$ for 6 min daily was reduced to 2.2 and $1.7 \%$ in experiments 1 and 2, respectively, and to 2.7 and $1.3 \%$ in experiments 1 and 2, respectively, when plants were exposed to UV-B at $0.8 \mathrm{~W} / \mathrm{m}^{2}$ for 2 min three times daily. Severity of powdery mildew on rosemary plants exposed to UV-B at $1.6 \mathrm{~W} / \mathrm{m}^{2}$ for 9 min once in 3 days was 5.3 and $1.2 \%$ in experiments 1 and 2, respectively, and 0.4 and $0.2 \%$ in experiments 1 and 2 , respectively, when treated with UV-B at $1.6 \mathrm{~W} / \mathrm{m}^{2}$ for $3 \mathrm{~min}$ daily. Powdery mildew severity was 3.5 and $2.7 \%$ in experiments 1 and 2, respectively, when plants were exposed to UV-B at $1.6 \mathrm{~W} / \mathrm{m}^{2}$ for 1 min three times daily. There was no visible phytotoxicity on rosemary plants following any of the UV-B treatments.

Use of reflective surfaces on greenhouse benches and efficacy of UV-B treatments. Although UV-B treatment significantly reduced powdery mildew severity on the adaxial leaf surface $(P<$ $0.0001)$, reflective bench cover did not affect that. On the other hand, UV-B $(P<0.0001)$, reflective bench cover $(P=0.002)$, and their interaction $(P=0.001)$ all significantly influenced the severity at the abaxial leaf surface. Covering the surface of the greenhouse bench with polished aluminum foil significantly reduced powdery mildew severity on the abaxial leaf side of strawberry plants when plants were exposed to nighttime UV-B $(P<0.0001$; Fig. 5A). Mean severity of the abaxial leaf side of plants exposed to nighttime UV-B without reflecting ground cover was $1.09 \%$, and it was reduced to $0.17 \%$ with such cover (Fig. 5A). The incidence of runner plants bearing 
colonies of powdery mildew was significantly reduced with UV-B ( $P$ $<0.0001)$ and reflective bench cover $(P=0.021)$ (Fig. 5B). About $29.7 \%$ of the runner plants bore powdery mildew colonies when exposed to UV-B with white plastic bench surfaces (Fig. 5B) compared with $11.1 \%$ of runner plants colonized when exposed to UV-B over benches with aluminum reflective surfaces (Fig. 5B). There was no significant interaction between treatments and experimental repeat. White plastic reflected $10 \%$ of UV within the range of 250 to $400 \mathrm{~nm}$, compared with $100 \%$ reflectance provided by the polished aluminum bench covers.

Efficacy of automated treatments of strawberry plants using a mobile boom. Severity of powdery mildew on the adaxial surfaces of strawberry leaves was significantly reduced following UV-B treatments wherein the mobile boom moved at speeds of $25 \mathrm{~cm} / \mathrm{min}(P=$ 0.003 , Fig. 6A) or $50 \mathrm{~cm} / \mathrm{min}(P=0.002$, Fig. 6B) compared with nontreated plants. Effects of experimental repeat and experimental repeat-UV-B treatment interaction were not significant. Therefore, severity data from two independent experiments were pooled for computation of treatment means and variances (Fig. 6). In experiments using a boom speed of $25 \mathrm{~cm} / \mathrm{min}$, severity of powdery mildew on control strawberry plants receiving GL only was 35.7 and $7.9 \%$ on adaxial and abaxial surfaces, respectively (Fig. 6A). Severity was reduced to $0.02 \%(P<0.0001)$ and $0.35 \%(P<0.0001)$, respectively, when plants were exposed to UV-B during the night (Fig. 6A). The addition of a directed airflow with the same UV-B treatment resulted in a disease severity of $0.03 \%(P<0.0001)$ and $2.2 \%(P<0.0001)$ on the adaxial and abaxial leaf sides, respectively, which represented a slight but significant increase in disease severity on the abaxial leaf surface with the directed airflow compared with without directed airflow (Fig. 6A).

In experiments using a boom speed of $50 \mathrm{~cm} / \mathrm{min}$, severity of powdery mildew on control strawberry plants receiving GL only was 22.7 and $3.3 \%$ on adaxial and abaxial surfaces, respectively (Fig. 6B). Severity was reduced to $0.16 \%(P<0.0001)$ and $0.18 \%(P<0.0004)$, respectively, when plants were exposed to UV-B during the night (Fig. 6B). The addition of a directed airflow with the same UV-B treatment resulted in a disease severity of $0.02 \%(P<0.0001)$ and $1.6 \%(P=0.07)$ on the adaxial and abaxial leaf sides, respectively. Again, this represented a slight but significant increase in disease severity on the abaxial leaf surface with the directed airflow compared with without directed airflow (Fig. 6B).

The incidence of strawberry runner plants bearing macroscopically visible mildew colonies was significantly reduced by UV-B treatments applied using mobile boom speeds of 25 and $50 \mathrm{~cm} / \mathrm{min}$ $(P<0.0001)$, whereas experimental repeat and experimental repeattreatment interactions were not significant. Therefore, incidence data from two independent experiments were pooled for computation of treatment means and variances (Fig. 7). Disease incidence reached 100 and $64 \%$ in nontreated controls for experiments using boom speeds of 25 and $50 \mathrm{~cm} / \mathrm{min}$, respectively (Fig. 7). The incidence of infection of runner plants was reduced to $1.4 \%(P<0.0001)$ and $2.1 \%(P<0.0001)$, respectively, if treated with UV-B or UV-B + additional air movement (Fig. 7). When the speed of the mobile boom was increased to $50 \mathrm{~cm} / \mathrm{min}$, use of directed airflow with UV-B applications resulted in a significant $(P<0.0001)$ and substantial increase in disease incidence compared with UV-B application without directed airflow (Fig. 7).

Addition of polished reflectors to lamps on the automated boom. Disease severity was significantly reduced on rosemary plants exposed to nighttime UV-B treatments with the automated boom $(P<0.0001)$, whereas experimental repeat and experimental repeat-UV-B treatment were not significant. Therefore, severity data from two independent experiments were pooled for computation of treatment means and variances (Fig. 8). Severity was $10 \%$ in untreated control plants. Severity was reduced $(P<0.0001)$ to $0.1 \%$ by nightly exposures to UV-B at $228.3 \mathrm{~J} / \mathrm{m}^{2} /$ day emitted from lamps without reflectors (Fig. 8), and was reduced $(P<0.0001)$ to $0.5 \%$ by alternate nightly exposures to UV-B at $395.8 \mathrm{~J} / \mathrm{m}^{2} /$ day emitted from lamps fitted with reflectors (Fig. 8).

Effect of UV-B doses applied using the automated boom on growth of strawberry and rosemary plants. In strawberry treated with UV-B using a boom speed of $25 \mathrm{~cm} / \mathrm{min}$, there was a significant reduction in number of runner plants $(P=0.005)$, leaf area $(P<$ $0.0001)$, and dry weight of the aboveground plant parts $(P=$ $0.0001)$ for the untreated control plants compared with the UV-B treatments (Table 1). When the speed of the boom was increased to $50 \mathrm{~cm} / \mathrm{min}$, differences in number of runner plants, leaf area, and dry weight between untreated controls and UV-B-treated plants were minor or insignificant (Table 1). Neither UV-B treatment, experimental repeat, nor experimental repeat-UV-B treatment affected the aboveground dry weight of rosemary plants $(P=0.0001)$.

\section{Discussion}

Within the test range, all treatments with UV-B significantly reduced powdery mildews of strawberry and rosemary compared with the untreated controls. The suppressive effects of UV-B on the two

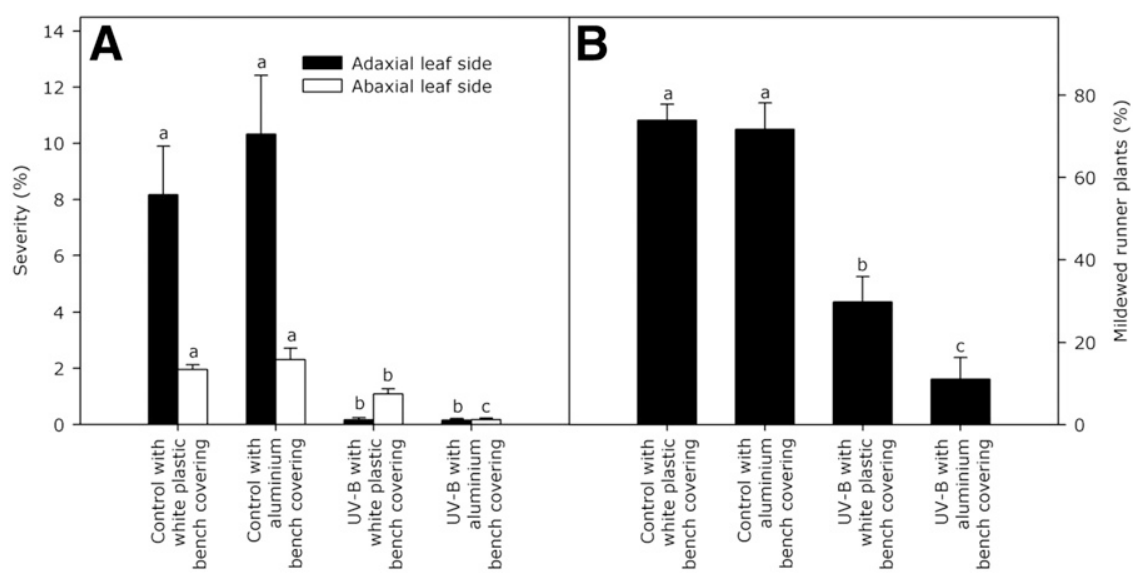

Fig. 5. Effect of reflective bench surfaces upon the degree of disease suppression provided by ultraviolet-B (UV-B) on severity of strawberry powdery mildew on the adaxial and abaxial surfaces of leaves of Korona strawberry. All plants were exposed to $16 \mathrm{~h}$ of growth light. Control plants were borne upon bench surfaces with white plastic or polished aluminum foil as bench cover, as were plants that received UV-B at $1.6 \mathrm{~W} / \mathrm{m}^{2}$ for 3 min daily. A, Disease severity was assessed separately for the adaxial and abaxial leaf surfaces as percentage of each leaf surface colonized 18 days after treatments were initiated. Assessed severity was adjusted to the quantity (1 + severity), log-transformed prior to analysis to induce homogeneity of variance, and then back-transformed to percentages for presentation. Bars represent the mean and standard error of three independent experiments, each with 6 replicate plants ( $n=18$ plants). Within each leaf surface category (adaxial or abaxial), different letters indicate significant differences in severity at $P=0.05$. B, Disease incidence was assessed as percentage of runner plants showing macroscopically visible mildew colonies at 18 days after initiation of treatments. Bars represent the mean and standard error of three independent experiments, each with 6 replicate plants $(n=18$ plants), and different letters indicate significant differences between treatment means at $P=0.05$. 
powdery mildews were generally equivalent at all tested combinations. It mattered far less whether the dose was administered in one or three events nightly or every third night (Fig. 4). This is an advantageous finding with respect to practical applications of UV-B in greenhouse and high-tunnel systems. It means that the scheduling of exposure events is flexible within the tested frequency, as long as an equal cumulative dose is applied. Although we did not observe phytotoxicity in the tested treatments, in the event that a single exposure with high dose resulted in phytotoxicity, the dose could be distributed across multiple events with less potential impact on host tissues.

We had anticipated, as had others (Michaloski 1991), that using a directed airflow to move foliage in combination with the UV-B applications would enhance the efficacy of treatments due to increased

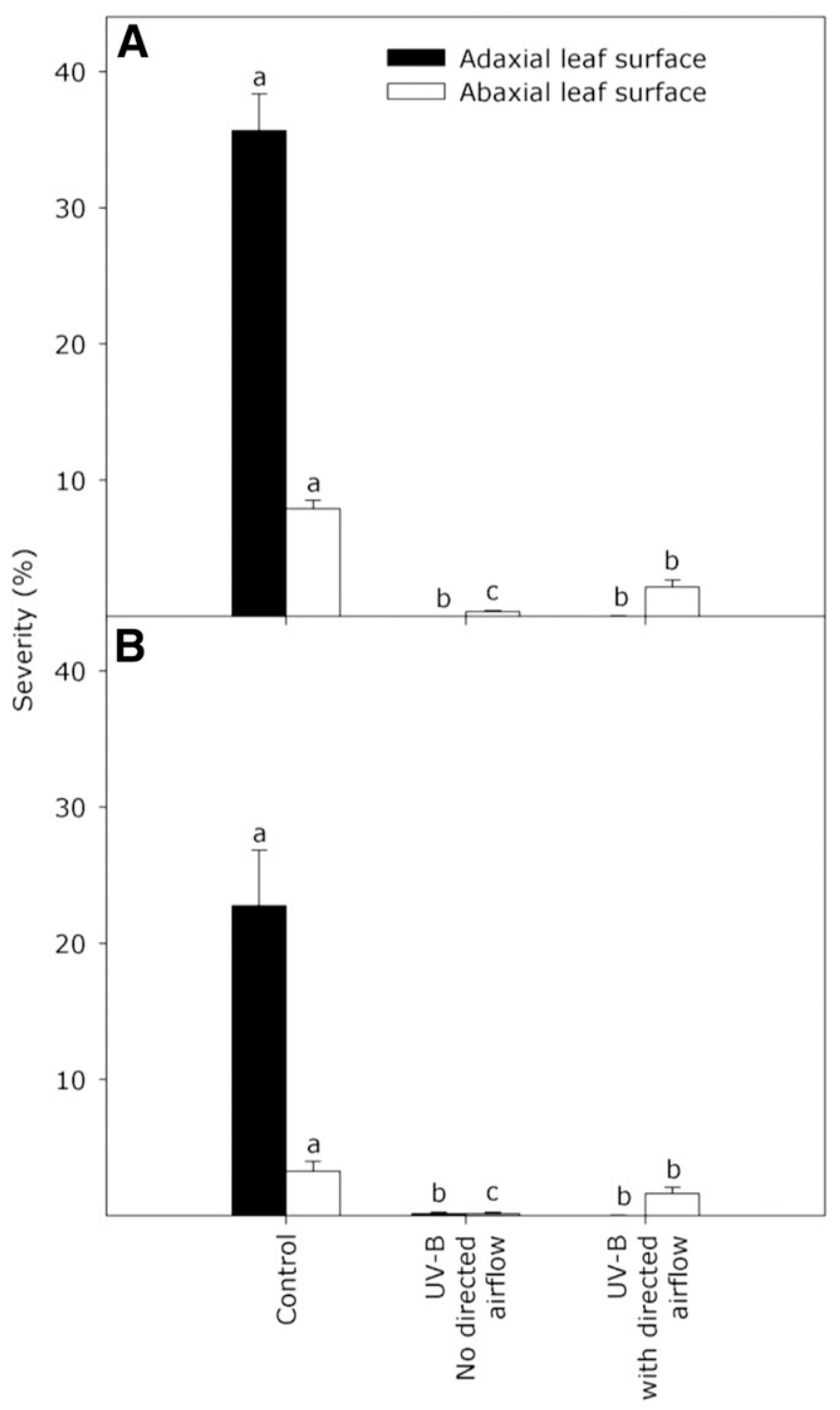

Fig. 6. Effect of directed airflow upon suppression of powdery mildew by ultraviolet-B (UV-B) irradiance on adaxial and abaxial leaf surfaces of Korona strawberry. Control plants received neither UV-B nor directed airflow. All plants were exposed to $16 \mathrm{~h}$ of growth light that delivered a minimum of $110 \pm 10 \mu \mathrm{mol} / \mathrm{m}^{2} / \mathrm{s}$. UV-B lamps were on an automated mobile boom that passed over the plants during the dark period that followed growth light illumination at a speed of A, 25 or B, $50 \mathrm{~cm} / \mathrm{min}$, either with or without an airflow of $2.5 \mathrm{~m} / \mathrm{s}$ created by an air blower attached to the mobile boom and directed toward the subtending plants. Disease severity was assessed separately for the adaxial and abaxial leaf surfaces as percentage of each leaf surface colonized 24 days after treatments were initiated. Assessed severity was adjusted to the quantity $(1+$ severity), log-transformed prior to analysis to induce homogeneity of variance, and then back-transformed to percentages for presentation. Bars represent the mean and standard error of two independent experiments, each with 12 replicate plants $(n=24$ plants) at the speed of 25 $\mathrm{cm} / \mathrm{min}$ and 6 replicate plants ( $n=12$ plants) at $50 \mathrm{~cm} / \mathrm{min}$. Different letters indicate significant differences between means at $P=0.05$. exposure of shaded and obscured tissues (especially the abaxial leaf surfaces). Instead, we found increased disease severity of the abaxial leaf surfaces in many treatments following the use of directed airflow. We speculate that this might be due to dispersal of conidia by the airstream before they are exposed to a lethal dose of UV-B.

Nighttime UV-B irradiances of 0.8 or $1.6 \mathrm{~W} / \mathrm{m}^{2}$ in durations of 2 to $18 \mathrm{~min}$ and at frequencies ranging from three times nightly to once every three nights reduced severity of powdery mildew by more than $90 \%$ on strawberry and rosemary plants compared with untreated controls. Use of polished aluminum reflectors behind lamps redirected the UV radiation toward plants, which nearly doubled the amount of UV-B energy that reached the plant canopy, especially on the adaxial leaf surfaces (Fig. 3), and allowed the same dose to be delivered in less time (Fig. 3) or at longer intervals between exposure events without increasing the number of lamps (Fig. 8). Use of polished aluminum foil as a reflective surface for greenhouse benches significantly increased the efficacy of UV-B in suppressing powdery mildew on abaxial leaf surfaces (Fig. 5). The ability of UV-B to reach the target organism directly or through reflectance is a critical issue that must be resolved for practical use of the technology to suppress disease. UV-B is completely absorbed by leaves. Thus, no UV-B will be transmitted through plant tissues, and shaded or obscured plant surfaces will not be effectively contacted by UV-B treatments. Polished aluminum foil surfaces reflected more than $95 \%$ of incoming UV-B energy (A. Suthaparan, unpublished data). Another potential method by which obscured and shaded tissues could be accessed is the use of a mobile boom, because considerable UV-B exposure occurs at a varying angle of incidence as the boom approaches, passes over, and then recedes from a given point (Fig. 3).

Our measurements of UV-B intensity at specific points as the lamps moved over a subtending surface indicated a changing angle of incidence that may result in UV-B reaching parts of the plant that would be obscured from a lamp that remained directly overhead. Thus, a mobile source may achieve some of the same goal of

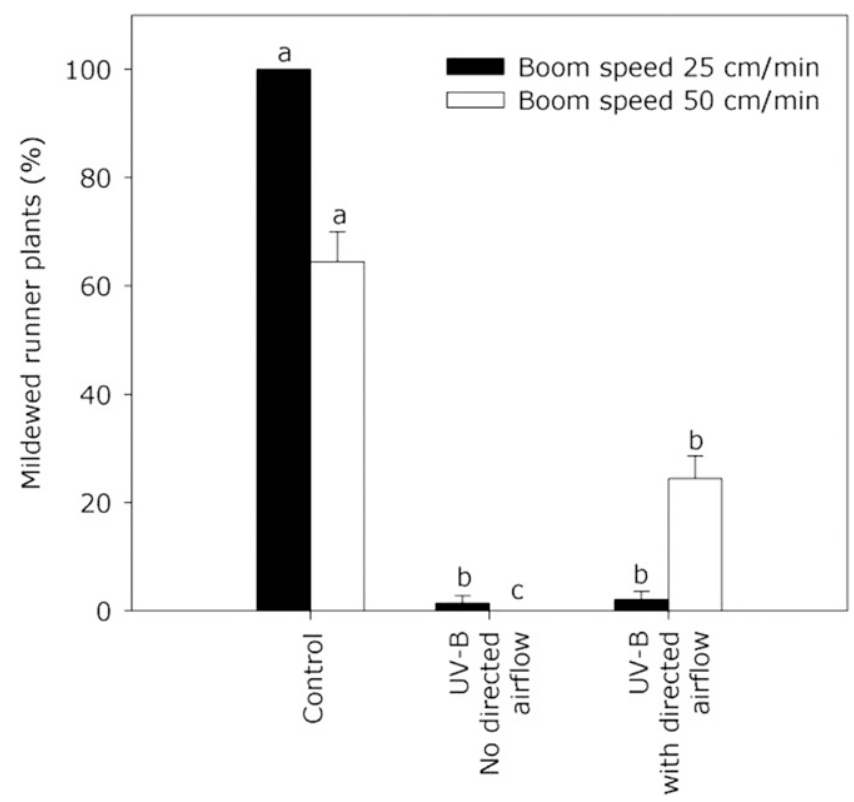

Fig. 7. Effect of directed airflow upon suppression of powdery mildew by ultraviolet-B (UV-B) irradiance on runner plants of Korona strawberry. Control plants received neither UV-B nor directed airflow. All plants were exposed to $16 \mathrm{~h}$ of growth light that delivered a minimum of $110 \pm 10 \mu \mathrm{mol} / \mathrm{m}^{2} / \mathrm{s}$. UV-B lamps were on an automated mobile boom that passed over the plants during the dark period that followed growth light illumination at a speed of 25 or $50 \mathrm{~cm} / \mathrm{min}$, either with or without an airflow of $2.5 \mathrm{~m} / \mathrm{s}$ created by an air blower attached to the mobile boom and directed toward the subtending plants. Disease was assessed 24 days after treatments were initiated as the percentage of runner plants that bore macroscopically visible mildew colonies. Bars represent the mean and standard error of two independent experiments, each with 12 replicate plants ( $n=24$ plants) at the speed of $25 \mathrm{~cm} / \mathrm{min}$ and 6 replicate plants ( $n=12$ plants) at $50 \mathrm{~cm} / \mathrm{min}$. Different letters indicate significant differences between means at $P=0.05$. 
penetration of UV-B into a complex plant canopy as might be achieved with directed air flow, without the potential of dispersing conidia of the pathogen.

Light and UV radiation have previously been reported for their potential in controlling powdery mildew at the experimental level (Schuerger and Brown 1997; Suthaparan et al. 2010a,b; Wang et al. 2010; Willocquet et al. 1996). In recent studies, the practical

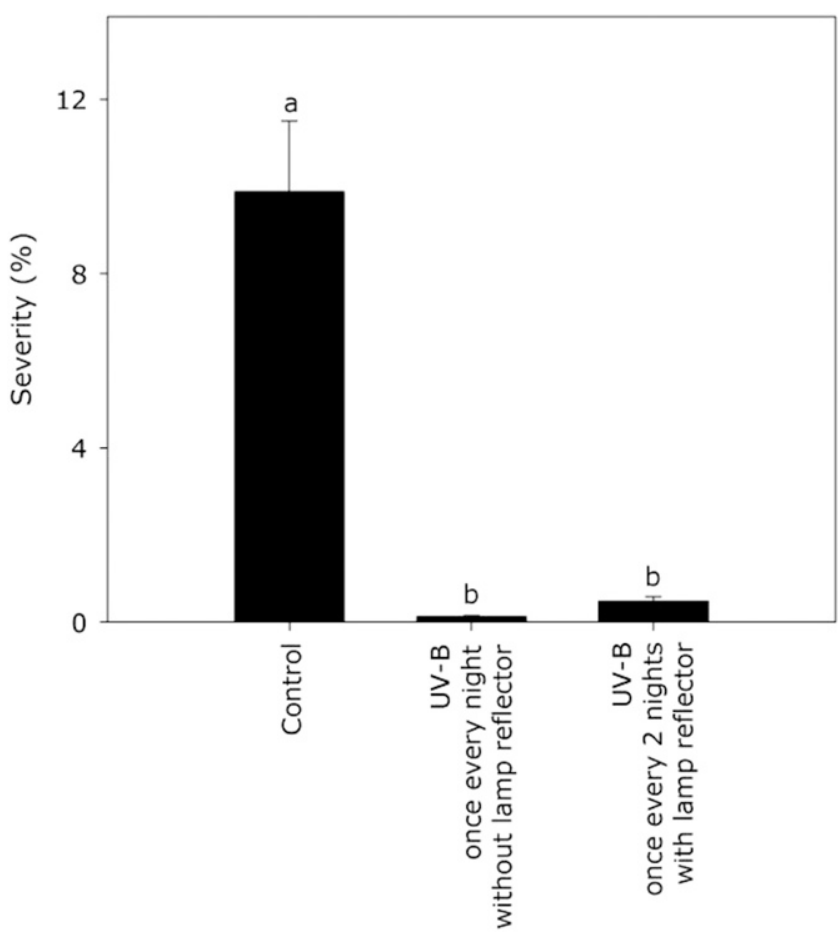

Fig. 8. Comparison of disease suppression provided by ultraviolet-B (UV-B) irradiance using lamps suspended from an automated boom with or without polished aluminum reflectors above the lamps. All plants of Rosy rosemary were exposed to $16 \mathrm{~h}$ of growth light at a minimum of $110 \pm 10 \mu \mathrm{mol} / \mathrm{m}^{2} / \mathrm{s}$. Control plants were not exposed to UV-B. Treated plants were exposed to UV-B radiation at a mobile boom speed of $50 \mathrm{~cm} / \mathrm{min}$ at the start of the dark period following growth light illumination either (i) daily using lamps without lamp reflectors or (ii) every second day using lamps with lamp reflectors. Severity was assessed as the percentage of total leaf area colonized at 24 days after start of the experiment. Assessed severity was adjusted to the quantity $(1+$ severity), log-transformed prior to analysis to induce homogeneity of variance, and then back-transformed to percentages for presentation. Bars represent the mean and standard error of the two independent experiments, each with six replicate pots having 5 plants in each pot ( $n=60$ plants). Different letters indicate significant differences at $P=0.05$.

Table 1. Efficiency of ultraviolet-B (UV-B) applied by an automated boom at speeds of either 25 or $50 \mathrm{~cm} / \mathrm{min}$ on growth of Korona strawberryw

\begin{tabular}{lcccc}
\hline Speed & Treatment $^{\mathbf{x}}$ & $\begin{array}{c}\text { Number of } \\
\text { runners }\end{array}$ & $\begin{array}{c}\text { Leaf } \\
\text { area }\left(\mathbf{c m}^{2}\right)^{\mathbf{y}}\end{array}$ & $\begin{array}{c}\text { Dry } \\
\text { weight }(\mathbf{g})^{\mathbf{z}}\end{array}$ \\
\hline $25 \mathrm{~cm} / \mathrm{min}$ & 1 & $5.4 \pm 0.27 \mathrm{~b}$ & $486.6 \pm 24.9 \mathrm{~b}$ & $4.3 \pm 0.26 \mathrm{~b}$ \\
& 2 & $6.7 \pm 0.31 \mathrm{a}$ & $677.6 \pm 25.9 \mathrm{a}$ & $6.2 \pm 0.30 \mathrm{a}$ \\
$50 \mathrm{~cm} / \mathrm{min}$ & 3 & $6.2 \pm 0.30 \mathrm{ab}$ & $637.4 \pm 27.2 \mathrm{a}$ & $5.6 \pm 0.30 \mathrm{a}$ \\
& 1 & $5.8 \pm 0.27 \mathrm{a}$ & $601.3 \pm 24.5 \mathrm{a}$ & $6.48 \pm 0.37 \mathrm{ab}$ \\
& 2 & $6.3 \pm 0.18 \mathrm{a}$ & $644.3 \pm 15.3 \mathrm{a}$ & $7.09 \pm 0.33 \mathrm{a}$ \\
& 3 & $6.3 \pm 0.30 \mathrm{a}$ & $619.5 \pm 30.9 \mathrm{a}$ & $5.90 \pm 0.44 \mathrm{~b}$ \\
\hline
\end{tabular}

w Values are mean and standard error of the mean of two repeated experiments with 12 replicates (plants) in each treatment $(n=24)$ at the speed of $25 \mathrm{~cm} / \mathrm{min}$ and 6 replicates (plants) in each treatment $(n=12)$ at the speed of $50 \mathrm{~cm} / \mathrm{min}$. Different letters between treatments in a column indicate significant differences at $P=0.05$.

$\times$ All treatments were exposed to $16 \mathrm{~h}$ of growth light at a minimum of $110 \pm$ $10 \mu \mathrm{mol} / \mathrm{m}^{2} / \mathrm{s}$, including the nontreated control (treatment 1 ); treatments 2 and 3 were exposed to UV-B in the dark, and treatment 3 received additional air movement during UV-B exposure.

${ }^{y}$ Leaf area of the unfolded leaves was measured by a leaf area meter

z Above soil plant parts were kept at $70^{\circ} \mathrm{C}$ in a drier for 10 days before weighing. potential of UV-B on powdery mildew disease management and optimization of its efficacy has been reported for cucumber and rose powdery mildew pathosystems (Suthaparan et al. 2012a,b,c), and UV-C has been used against strawberry powdery mildew (Janisiewicz et al. 2015). Rapid development of modern lighting sources (light emitting diodes [LEDs]) (Bourget 2008; Morrow 2008) with specific spectral qualities (including UV-B) and energy efficiencies could enable selective application of various spectra against powdery mildew or other diseases in commercial greenhouses. However, presently available LEDs do not produce sufficient energy in the effective region (near $280 \mathrm{~nm}$ ) for suppression of powdery mildew (Suthaparan et al. 2016). Nonetheless, we have demonstrated that effective suppression is not dependent upon new lamp technology. Effective suppression has been demonstrated using inexpensive and widely available UV-B fluorescent lamps.

Heterogeneity of light distribution within the greenhouse due to the shading effect of UV-B fluorescence tubes and their fixtures and ballast, as well as potential disturbance of such lamps in daily greenhouse activities, could also limit their practical use. The present study addresses some of these limitations by using an automated boom to move the UV-B lamps over the crop. Many modern commercial greenhouses use permanently installed automated mobile spray booms which could be retrofitted with UV-B lamps. Further, nighttime application largely circumvents the risks for worker exposure to UV-B. We are currently adapting this technology for use on horizontal and vertical booms of commercially available spray equipment, as well as laterally placed stationary UV-B lamps, for use against powdery mildews in commercial production of fruit, vegetables, and ornamental plants.

\section{Acknowledgments}

This research was financed by Oslofjordfondet and The Norwegian Growers' Association. We thank I. K. Hagen for her valuable assistance and the technicians at the Centre for Plant Research and Department of Mathematics and Technology.

\section{Literature Cited}

Bourget, C. M. 2008. An introduction to light emitting diodes. HortScience 43 1944-1946.

Gadoury, D. M., Pearson, R. C., Seem, R. C., Henick-Kling, T., Creasy, L. L., and Michaloski, A. 1992. Control of fungal diseases of grapevine by short-wave ultraviolet light. (Abstr.) Phytopathology 82:243.

Hollomon, W. D., and Wheeler, E. I. 2002. Controlling powdery mildews with chemistry. Pages 249-255 in: The Powdery Mildews. A Comprehensive Treatise. R. R. Bélanger, R. W. Bushnell, J. A. Dick, and W. L. T. Carver, eds. American Phytopathological Society, St. Paul, MN.

Janisiewicz, W. J., Takeda, F., Jurick, W., Nichols, B., Wolford, S., and Glenn, D. M. 2015. A novel approach to control gray mold, anthracnose, and powdery mildew on strawberry using low-dose UV-C irradiation. (Abstr.) Phytopathology 105:S4.64.

Jones, H., Whipps, J. M., and Gurr, S. J. 2001. The tomato powdery mildew fungus Oidium neolycopersici. Mol. Plant Pathol. 2:303-309.

Kiss, L. 2003. A review of fungal antagonists of powdery mildews and their potential as biocontrol agents. Pest Manage. Sci. 59:475-483.

McGrath, M. T. 2001. Fungicide resistance in cucurbit powdery mildew: Experiences and challenges. Plant Dis. 85:236-245.

McGrath, M. T., Staniszewska, H., and Shishkoff, N. 1996. Fungicide sensitivity of Sphaerotheca fuliginea populations in the United States. Plant Dis. 80:697-703.

Michaloski, A. 1991. A method and apparatus for ultraviolet treatment of plants. U.S. Patent No. 5,040,329.

Morrow, R. C. 2008. LED lighting in horticulture. HortScience 43:1947-1950.

Mortensen, L. M., Pettersen, R. I., and Gislerød, H. R. 2007. Air humidity variation and control of vase life and powdery mildew in cut roses under continuous lighting. Eur. J. Hortic. Sci. 72:255-259.

Newsham, K. K., Oxborough, K., White, R., Greenslade, P. D., and McLeod, A. R. 2000. UV-B radiation constrains the photosynthesis of Quercus robur through impacts on the abundance of Microsphaera alphitoides. For. Pathol. 30:265-275.

Paulitz, T. C., and Belanger, R. R. 2001. Biological control in greenhouse systems. Annu. Rev. Phytopathol. 39:103-133.

Romero, D., de Vicente, A., Zeriouh, H., Cazorla, F. M., Fernández-Ortuño, D. Torés, J. A., and Pérez-García, A. 2007. Evaluation of biological control agents for managing cucurbit powdery mildew on greenhouse-grown melon. Plant Pathol. 56:976-986.

Schuerger, A. C., and Brown, C. S. 1997. Spectral quality affects disease development of three pathogens on hydroponically grown plants. HortScience 32:96-100. 
Suthaparan, A., Solhaug, K. A., Stensvand, A., and Gislerød, H. R. 2016. Determination of UV action spectra affecting the infection process of Oidium neolycopersici, the cause of tomato powdery mildew. J. Photochem. Photobiol. B 156:41-49.

Suthaparan, A., Stensvand, A., Solhaug, K. A., Torre, S., Mortensen, L. M., Gadoury, D. M., and Gislerød, H. R. 2012a. Interruption of the night period by UV-B suppresses powdery mildew of rose and cucumber. Acta Hortic. 956:617-620.

Suthaparan, A., Stensvand, A., Solhaug, K. A., Torre, S., Mortensen, L. M., Gadoury, D. M., Seem, R. C., and Gislerod, H. R. 2012b. Suppression of powdery mildew (Podosphaera pannosa) in greenhouse roses by brief exposure to supplemental UV-B radiation. Plant Dis. 96:1653-1660.

Suthaparan, A., Stensvand, A., Solhaug, K. A., Torre, S., Telfer, K. H., Ruud, A. K., Davidson, L. C., Mortensen, L. M., Gadoury, D. M., Seem, R. C., and Gislerod, H. R. 2012c. Suppression of cucumber powdery mildew by UV-B is affected by background light quality. (Abstr.) Phytopathology 102:S4.116.

Suthaparan, A., Stensvand, A., Solhaug, K. A., Torre, S., Telfer, K. H., Ruud, A. K., Mortensen, L. M., Gadoury, D. M., Seem, R. C., and Gislerød, H. R. 2014. Suppression of cucumber powdery mildew by supplemental UV-B radiation in greenhouses can be augmented or reduced by background radiation quality. Plant Dis. 98:1349-1357.

Suthaparan, A., Stensvand, A., Torre, S., Herrero, M. L., Pettersen, R. I., Gadoury, D. M., and Gislerød, H. R. 2010a. Continuous lighting reduces conidial production and germinability in the rose powdery mildew pathosystem. Plan Dis. 94:339-344.

Suthaparan, A., Torre, S., Stensvand, A., Herrero, M. L., Pettersen, R. I., Gadoury, D. M., and Gislerød, H. R. 2010b. Specific light emitting diodes can suppress sporulation of Podosphaera pannosa on greenhouse roses. Plant Dis. 94: $1105-1110$.

Wang, H., Jiang, Y. P., Yu, H. J., Xia, X. J., Shi, K., Zhou, Y. H., and Yu, J. Q 2010. Light quality affects incidence of powdery mildew, expression of defence related genes and associated metabolism in cucumber plants. Eur. J. Plant Pathol. 127:125-135.

Willocquet, L., Colombet, D., Rougier, M., Fargues, J., and Clerjeau, M. 1996 Effects of radiation, especially ultraviolet $\mathrm{B}$, on conidial germination and mycelial growth of grape powdery mildew. Eur. J. Plant Pathol. 102:441-449.

Willocquet, L., Sombardier, A., Blancard, D., Jolivet, J., and Savary, S. 2008. Spore dispersal and disease gradients in strawberry powdery mildew. Can. J. Plant Pathol. 30:434-441. 